\title{
Circulating Insulin-Like Growth Factor I Mediates Exercise-Induced Increases in the Number of New Neurons in the Adult Hippocampus
}

\author{
José Luis Trejo, Eva Carro, and Ignacio Torres-Alemán \\ Laboratory of Neuroendocrinology, Cajal Institute, Consejo Superior de Investigaciones Científicas, 28002 Madrid, Spain
}

\begin{abstract}
Although the physiological significance of continued formation of new neurons in the adult mammalian brain is still uncertain, therapeutic strategies aimed to potentiate this process show great promise. Several external factors, including physical exercise, increase the number of new neurons in the adult hippocampus, but underlying mechanisms are not yet known. We recently found that exercise stimulates uptake of the neurotrophic factor insulin-like growth factor I (IGF-I) from the bloodstream into specific brain areas, including the hippocampus. In addition, IGF-I participates in the effects of exercise on hippocampal c-fos expression and mimics several other effects of exercise on brain function. Because subcutaneous administration of IGF-I to sedentary adult rats markedly increases the number of new neurons in the hippocampus, we hypothesized that exercise-induced brain uptake of blood-borne IGF-I could mediate the stimulatory effects of exercise on the adult hip-
\end{abstract}

pocampus. Thus, we blocked the entrance of circulating IGF-I into the brain by subcutaneous infusion of a blocking IGF-I antiserum to rats undergoing exercise training. The resulting inhibition of brain uptake of IGF-I was paralleled by complete inhibition of exercise-induced increases in the number of new neurons in the hippocampus. Exercising rats receiving an infusion of nonblocking serum showed normal increases in the number of new hippocampal neurons after exercise. Thus, increased uptake of blood-borne IGF-I is necessary for the stimulatory effects of exercise on the number of new granule cells in the adult hippocampus. Taken together with previous results, we conclude that circulating IGF-I is an important determinant of exercise-induced changes in the adult brain.

Key words: insulin-like growth factor I; adult neurogenesis; brain effects of exercise; blood-CSF barrier; brain uptake; neurotrophic factors
Recent evidence emphasizes the pleiotropic effects of insulin-like growth factor I (IGF-I) on brain cells. Although most of the work has focused on the actions of IGF-I in the developing brain (Feldman et al., 1997), new data strongly suggest an important role of this growth factor in adult brain physiology and disease (Torres-Aleman, 1999). In this regard, it is intriguing to consider as a possibility that blood-borne IGF-I might constitute an essential trophic input to the adult brain because levels of circulating IGFs are altered in all types of neurodegenerative diseases studied so far, including major illnesses such as Alzheimer's disease or stroke (Busiguina et al., 2000). It is thus important to establish whether circulating IGF-I plays a role in the brain, possibly as a physiological neuroprotectant. Of note, whereas serum IGF-I has long been considered a major effector of growth hormone $(\mathrm{GH})$ actions on somatic growth, recent evidence with liver-specific IGF-I null mutants showing normal body growth disputes this notion because these mice have very low levels of circulating IGF-I (Sjogren et al., 1999). Thus, the physiological role of blood-borne IGF-I is not clear.

To analyze the role of circulating IGF-I on brain function under physiological conditions, we have taken advantage of the fact that stimuli such as physical exercise activate the GH-IGF-I

\footnotetext{
Received July 6, 2000; revised Dec. 13, 2000; accepted Dec. 13, 2000.

This work was supported by Grants PM97-0018 from Direccion General de Enseñanza Superiore Investigación Científica and 08.5/0051/98 from Comunidad Autonoma de Madrid (CAM). E.C. is a CAM postdoctoral fellow. We thank Joaquin Sancho and Fernando Lozano for their expert help.

Correspondence should be addressed to Ignacio Torres-Aleman, Cajal Institute, Consejo Superior de Investigaciones Científicas, Avenida Dr. Arce 37, $28002 \mathrm{Ma}$ drid, Spain. E-mail: torres@cajal.csic.es.

Copyright (C) 2001 Society for Neuroscience 0270-6474/01/211628-07\$15.00/0
}

axis, resulting in increased uptake of circulating IGF-I by target organs such as the muscle (Eliakim et al., 1997) and the brain (Carro et al., 2000). Furthermore, at least several of the effects of exercise on the brain are likely mediated by IGF-I, including increased hippocampal expression of brain-derived neurotrophic factor (BDNF) and c-fos activation (Carro et al., 2000). Recently, it has been shown that another effect of exercise on the adult brain is to increase the number of new neurons in the adult hippocampus (van Praag et al., 1999). Because peripheral administration of IGF-I also results in increases in the number of new neurons in the hippocampus of hypophysectomized rats (Aberg et al., 2000), we speculated that circulating IGF-I might be mediating the stimulatory effects of exercise on the number of new hippocampal neurons in normal adult rats.

There is now general agreement that new neurons are continuously produced in the hippocampal dentate gyrus of adult mammals. These new neurons are generated from a local population of progenitor cells located in the subgranular zone (Gage et al., 1998), following an outside-in gradient with the oldest cells located on the molecular edge and the youngest ones on the hilar edge of the granule cell layer (Crespo et al., 1986). Importantly, these new adult-generated neurons develop dendritic and axonal processes and receive synaptic contacts on their cell bodies (Stanfield and Trice, 1988).

There are at least two issues of great relevance in the study of the production and survival of new neurons in the adult hippocampus. First, it is possible that changes in the relative proportion of young neurons produced by modulatory factors may influence hippocampal circuitry. Second, factors and mechanisms underlying the formation and survival of new neurons in the adult 
brain are of potential therapeutic importance. Thus, external stimulators of the number of new neurons in the hippocampal formation, such as exercise may modulate hippocampal function as well as exert neuroprotective actions on hippocampal-related pathological disturbances.

We now show that exercise-induced increases in the number of new neurons in the adult hippocampus depend on the entrance of IGF-I from the circulation into the brain.

\section{MATERIALS AND METHODS}

Experimental procedures. Male Wistar rats (300 gm) from our in-house colony were used. Because the aim of the study was to determine the role of IGF-I on exercise-induced changes in the number of new neurons in the hippocampus, we followed a protocol similar to that originally reported by van Praag et al. (1999) to determine the effects of exercise on the number of new neurons in the adult hippocampus. In a first series of experiments we administered an IGF-I inf usion through a subcutaneous osmotic minipump (Alzet 2001; $50 \mu \mathrm{g} \cdot \mathrm{kg}^{-1} \cdot \mathrm{d}^{-1}$, rate of infusion 1 $\mu \mathrm{l} / \mathrm{hr}$ ) for $7 \mathrm{~d}$ to normal rats, as described (Fernandez et al., 1998). Control animals received a saline infusion. Simultaneously, both IGF-Iinfused and control animals received daily intraperitoneal injections of BrdU (Sigma, St. Louis, MO) dissolved in $0.9 \% \mathrm{NaCl}$ at a dose of 50 $\mathrm{mg} / \mathrm{kg}$ for $7 \mathrm{~d}$. Animals were anesthetized and killed either $24 \mathrm{hr}$ (short-term) or 3 weeks (long-term) after the last injection of BrdU (days 8 and 30 , respectively). $\mathrm{BrdU}^{+}$cells found after short-term and longterm survival will include newly formed cells that have survived up to 1 week and 1 month, respectively.

In a second series of experiments aimed to determine the role of endogenous blood-borne IGF-I in exercise-induced changes in the number of new neurons in the adult hippocampus, we administered an infusion of a blocking anti-IGF-I antiserum (20\% in saline; Alzet osmotic minipump 1002, subcutaneously implanted, with an infusion rate of $0.25 \mu \mathrm{l} / \mathrm{hr}$ ) to a group of rats running in a treadmill for $15 \mathrm{~d}$ (see below). The control group of exercising animals received an infusion of nonimmune normal rabbit serum (NRS; $20 \%$ in saline) because pilot experiments indicated that exercising rats receiving either a saline infusion or NRS show identical increases in the number of labeled cells in the hippocampus. All animals received BrdU injections during the $15 \mathrm{~d}$ of the study. Thereafter, one group was killed $24 \mathrm{hr}$ after the last injection of $\mathrm{BrdU}$ (day 16) to determine short-term survival of $\mathrm{BrdU}^{+}$cells, whereas a second group was killed 2 weeks later for long-term survival analysis (day 30). In all cases, a decrease in the number of $\mathrm{BrdU}^{+}$nuclei in long-term cell survival experiments was found as compared with short-term studies. This indicates a natural cell death process of the newly born cells along time (Cameron et al., 1993).

IGF-I antibody and immunoassay. The anti-IGF-I antiserum used for blocking experiments has $<1 \%$ cross-reactivity with either insulin or IGF-II, as determined by competition with ${ }^{125}$ I-IGF-I. IGF-I levels in the CSF were determined by radioimmunoassay as described (Carro et al., 2000). CSF samples $(150-200 \mu l)$ were obtained from the cisterna magna.

Treadmill running. Animals were familiarized with the treadmill apparatus (Letica, Germany) to minimize novelty stress and then divided in two groups: exercised and nonexercised. The procedures followed are described in detail elsewhere (Carro et al., 2000).The exercise group ran for $1 \mathrm{hr}$ at $17 \mathrm{~m} / \mathrm{min}$ for 2 weeks, whereas the control group remained in the treadmill without running.

Immunohistochemistry. Animals were perfused transcardially with $4 \%$ paraformaldehyde in $0.1 \mathrm{M}$ phosphate buffer ( $\mathrm{PB}, \mathrm{pH}$ 7.4). Brains were removed and post-fixed $24 \mathrm{hr}$ at $4^{\circ} \mathrm{C}$. The rostral-septal half of the right hippocampus was dissected out, and the brain was cut rostrally at bregma $-1.30 \mathrm{~mm}$, caudally at bregma $-5.80 \mathrm{~mm}$, and ventrally at $4.5 \mathrm{~mm}$ (Paxinos and Watson, 1982). The areas were serially sectioned rostrocaudally with a Leica vibratome at $50 \mu \mathrm{m}$ and immersed free-floating in 0.1 M PB. Ninety-six well plates were used to keep the sections separate to preserve the order of the series. Left hippocampi were coronally sectioned at $30-\mu \mathrm{m}$-thick for IGF-I immunohistochemistry.

A one-in-six series of sections of every animal was used for stereology of cell counts. Four series were used for double-labeling and analysis of phenotypes by confocal microscopy (Leitz, Wetzlar, Germany), and another series was used for Nissl staining. Cell-specific markers used were: $\beta$-tubulin-III for neurons (Easter, et al., 1993), glial fibrillary acidic-protein (GFAP) (Boyes et al., 1986; Cameron et al., 1993), and vimentin (Pixley and de Vellis, 1984; Cameron et al., 1993) for glial cells. Incubations were performed in PB $0.1 \mathrm{M}$ with $0.5 \%$ Triton X-100 and $0.1 \%$ bovine serum albumin. Sections were blocked by incubating for 15 min in a solution with $10 \%$ methanol and $3 \%$ hydrogen peroxide. For BrdU immunohistochemistry, DNA was denatured with a 30 min incubation in $\mathrm{HCl} 2 \mathrm{~N}$ at room temperature. Primary antibodies used were mouse anti-BrdU (Hybridoma Bank, Iowa City, IA) 1:20,000; mouse anti- $\beta$ tubulin III (Promega, Madison, WI) 1:60,000; mouse anti-GFAP (Sigma) 1:2000; rabbit anti-vimentin (Boehringer Mannheim, Mannheim, Germany) 1:100; and rabbit IGF-IR 1:1000 (Garcia-Segura et al., 1997). For single BrdU immunohistochemistry performed for stereology counts, the secondary antibody used was a biotinylated donkey antimouse IgG (Jackson ImmunoResearch, West Grove, PA) 1:1,000 followed by the peroxidase-based ABC system (Vector Laboratories, Burlingame, CA) using diaminobenzidine as the chromogen. For double immunohistochemistry we used streptavidin-Alexa 488 (Molecular Probes, Eugene, OR) 1:2000 after the secondary biotinylated antibody and anti-rabbit IgG-Alexa 594 or anti-mouse IgG-Alexa 594 (Molecular Probes) 1:2000. When both primary antibodies were generated in mice, incubations with antibodies for each antigen were done sequentially, taking advantage of the fact that BrdU staining localizes to the cell nucleus, whereas cell-specific markers used are present in the cytoplasm. In addition, the type of secondary antibody used was inverted in several experiments to insure specificity: nuclear BrdU staining is either greenyellow when using Alexa 488 or red with Alexa 594 (see Fig. 2C,F). IGF-I immunohistochemistry was performed with a polyclonal anti-IGF-I 1:500 (Carro et al., 2000), followed by a biotinylated goat anti-rabbit IgG (Pierce, Rockford, IL) 1:300. A third amplification step was used with streptavidin-Alexa 488 (Molecular Probes) 1:1000.

For stereology, BrdU-positive cells were counted in a one-in-six series of sections $(300 \mu \mathrm{m}$ apart) with a $40 \times$ objective (Leica) throughout the rostral-septal half of the granule cell layer (from the rostralmost extreme of the hippocampus, at bregma $-1.30 \mathrm{~mm}$, to the caudal end, at bregma $-5.80 \mathrm{~mm}$ ). The same areas and number of sections were studied for all the animals and all the experimental groups. We considered as $\mathrm{BrdU}^{+}$those nuclei completely filled with $\mathrm{DAB}$ product or fluorescent marker or showing patches of variable intensity. We used the optical dissector technique to estimate the cell density of $\mathrm{BrdU}^{+}$cells in the granule cell layer as described by Howard and Reed (1998), and expressed it as the number of positive cells per cubic millimeter. We used total section thickness for dissector height (Hatton and von Bartheld, 1999) and a counting frame of $55 \times 55 \mu \mathrm{m}$, as detailed elsewhere (Azcoitia et al., 1999). Adjacent Nissl-stained sections were used to measure the width of the granule cell layer. The granule cell area was traced using a camera lucida, and drawings were scanned with a CanoScan 600 (Canon) and processed with ScionImage 3b software to determine the mean width of the granule cell layer throughout the rostrocaudal extent of the studied region. No significant differences were found between experimental groups in the width of the granule cell layer.

Double immunohistochemistry was performed in adjacent sections in one-in-six series of every animal. We counted three or four areas in each section for five or six sections in each animal. The assignment of each BrdU-positive cell to a category of neuronal, glial, or other, unidentified type was done by a researcher unaware of group treatments by moving the confocal plane up and down of the $z$-axis along the entire segment in which every cell appeared (see Fig. $2 H-L$ ). The width of the section studied in all cases oscillated between 15 and $20 \mu \mathrm{m}$. Only those $\mathrm{BrdU}^{+}$ nuclei with colocalization of $\beta$-tubulin in the cytoplasm along the successive planes of the $z$-axis were considered as neurons. Data are presented as percentage of neurons per glial cells or other, unidentified BrdU-positive cells. A $t$ test was performed when comparing two groups, and a one-way ANOVA was used for comparing multiple groups. Post hoc comparisons were made with a Newman-Keuls test.

\section{RESULTS}

\section{Inhibition of brain uptake of blood-borne IGF-I}

We first tested whether chronic subcutaneous administration of an anti-IGF-I antiserum could block the exercise-induced entrance of circulating IGF-I into the brain. As shown in Figure $1 A$, infusion of the anti-IGF-I antiserum to rats undergoing exercise training results in absence of brain IGF-I labeling. However, control exercising rats receiving a nonblocking, NRS infusion show the expected increase in brain IGF-I labeling, as compared 

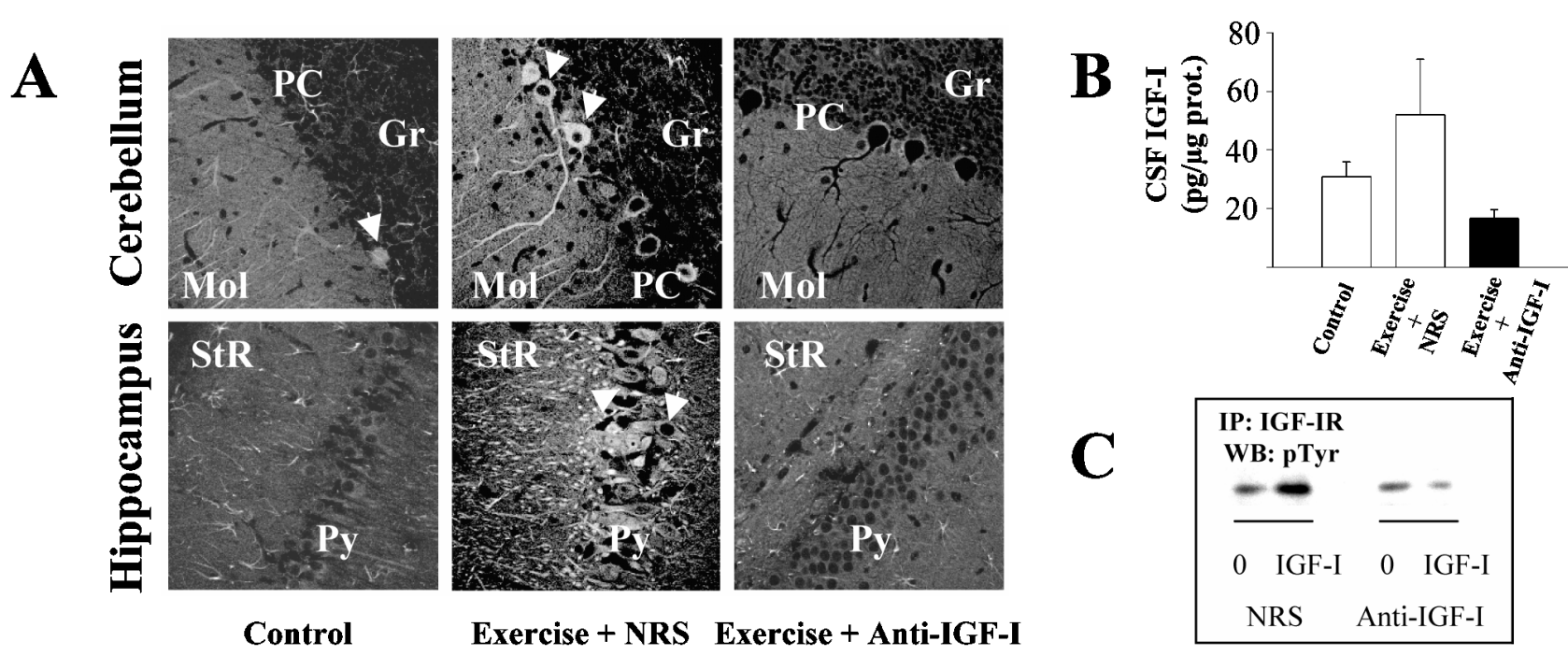

Figure 1. Infusion of an anti-IGF-I antiserum inhibits exercise-induced brain uptake of circulating IGF-I. $A$, Control sedentary animals show very low IGF-I labeling in the brain. Rats running in a treadmill for $15 \mathrm{~d}$ and receiving a simultaneous infusion of a nonblocking normal rabbit serum (NRS) show marked increases in IGF-I labeling throughout the brain. However, animals undergoing the same exercise schedule but receiving an infusion of an anti-IGF-I antiserum do not show increased brain IGF-I labeling. The cerebellar cortex and the hippocampus are shown as representative areas accumulating IGF-I after exercise (see references for further details). Arrows indicate typically labeled neurons. Mol, Cerebellar molecular layer; $P C$, Purkinje cell layer; $G r$, cerebellar granule cell layer; $P$, hippocampal pyramidal cell layer; StR, hippocampal stratum radiatum. $B$, Levels of IGF-I in the CSF of exercising animals receiving an infusion of NRS are $68 \%$ higher than in control, sedentary animals. However, exercising rats receiving an anti-IGF-I infusion do not show increased CSF IGF-I levels; $n=3$ per group. $C$, The anti-IGF-I antibody used for blocking uptake of IGF-I blocks interaction of IGF-I with its receptor. The presence of the anti-IGF-I antiserum ( $20 \%$ in culture medium) completely blocks IGF-I-induced receptor tyr-phosphorylation in cerebellar neuronal cultures (right). When $20 \%$ NRS was used instead, IGF-I receptor was tyr-phosphorylated in response to IGF-I (left), indicating normal biological activity of IGF-I. Cerebellar cultures were lysed 3 min after addition of 100 nM IGF-I, immunoprecipitated (IP) with a polyclonal anti-IGF-I receptor antibody, and blotted $(W B)$ with a monoclonal anti-pTyr antibody.

with normal sedentary rats. In support of the idea that the IGF-I antiserum is blocking the entrance of IGF-I from the blood stream into the CSF (Carro et al., 2000), we also found that infusion of the blocking anti-IGF-I antiserum, but not the NRS, results in blockade of exercise-induced increases in CSF IGF-I levels (Fig. $1 B$ ). Although we cannot exclude the possibility that the IGF-I rabbit antiserum, but not the normal rabbit serum, crosses the blood-brain barriers and directly affect $\mathrm{BrdU}^{+}$cells, our results support the idea that the IGF-I antiserum blocks passage of IGF-I through the blood-CSF barrier by its ability to bind circulating IGF-I. As shown in Figure $1 C$, the anti-IGF-I antiserum blocks interaction of IGF-I with its receptor: IGF-Iinduced tyrosine phosphorylation of the IGF-I receptor is blocked in the presence of $20 \%$ anti-IGF-I but not $20 \%$ NRS.

\section{IGF-I increases the number of BrdU-labeled cells in the hippocampus of normal adult rats}

Cells incorporating BrdU were found in the hippocampal formation of all experimental groups. $\mathrm{BrdU}^{+}$nuclei were detected both in the granule cell layer and in the dentate hilus. However, we only analized cells in the granule layer (GCL) because only sparse $\mathrm{BrdU}^{+}$nuclei could be found in the dentate hilus, representing $<5 \%$ of total labeled nuclei (Fig. $2 A, B$ ). BrdU ${ }^{+}$cells in the GCL appeared distributed following a gradient. In the most-medial aspect, where the suprapyramidal and infrapyramidal blades join, we frequently found a dense group of positive nuclei. In the medial half of the granule layer the nuclei arranged along a line, with some gaps in between. In the lateral half of the layers $\mathrm{BrdU}^{+}$ cells became uneven and more scarce. The great majority of positive nuclei were found in the inner part of the granule layer. Distribution of $\mathrm{BrdU}^{+}$cells was similar in all groups.

To determine a possible role of peripheral IGF-I in the in- crease of BrdU-labeled cells induced by exercise in the hippocampus, we first analyzed whether administration of IGF-I could mimic the stimulatory effects of exercise. Although recent results indicate that peripheral administration of IGF-I does increase the number of $\mathrm{BrdU}^{+}$nuclei in the hippocampus, this effect was observed in hypophysectomized animals (Aberg et al., 2000), making it difficult to rule out interferences by ensuing hormonal derangements. In addition, the stimulatory effects of exercise on the number of new hippocampal neurons have been reported on intact animals (van Praag et al., 1999).

As shown in Figure $3 A$, subcutaneous administration of IGF-I with a minipump for $7 \mathrm{~d}$ results in a significant increase in the number of $\mathrm{BrdU}^{+}$-positive cells in the hippocampal dentate gyrus both after $24 \mathrm{hr}(p<0.05)$ as well as 3 weeks after the last BrdU injection $(p<0.005)$.

To determine whether $\mathrm{BrdU}^{+}$cells can directly respond to IGF-I, we labeled them with an anti-IGF-I receptor antibody and found that $\mathrm{BrdU}^{+}$cells located in the granule cell layer express IGF-I receptors (Fig. 2). We also determined the phenotype of $\mathrm{BrdU}^{+}$cells in the hippocampus by double-labeling with cellspecific markers. As previously reported (Kosaka and Hama, 1986), the great majority of labeled nuclei in the GCL express the neuronal marker $\beta$-tubulin III (Fig. 2), whereas only a minority were labeled with a glial cell marker (GFAP, Fig. 2; in the GCL, the number of glial cells is negligible). Furthermore, and in agreement with previous observations (van Praag et al., 1999), a substantial proportion of labeled nuclei could not be clearly identified as glia or neurons. Unidentified cells were also negative for calbindin-D28k and vimentin, a neuronal and glial cell markers, respectively. Thus, the lineage of these cells cannot be determined with these markers. Treatment with IGF-I did not favor 

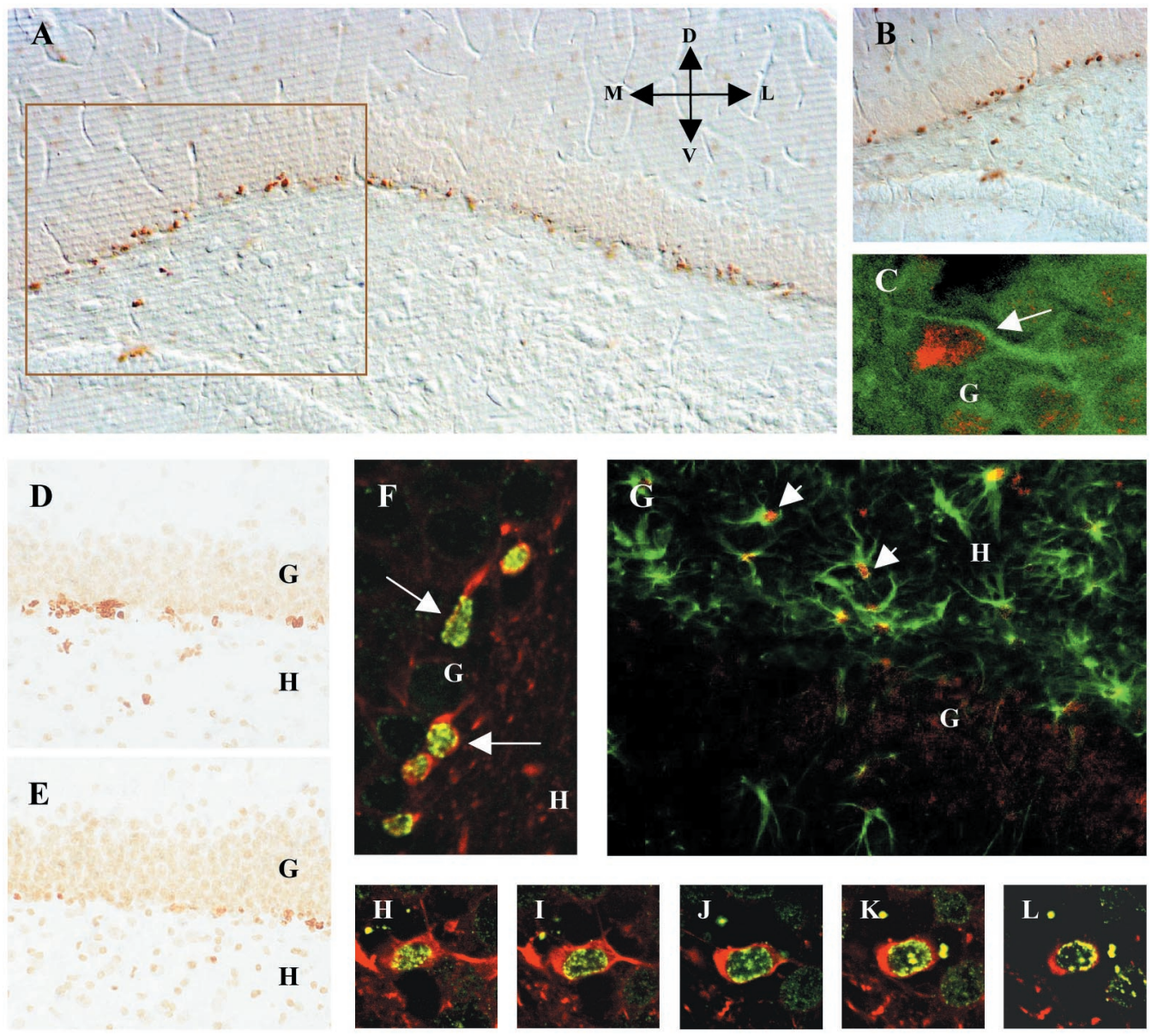

Figure 2. Characterization of BrdU-labeled cells in the granule cell layer of the adult hippocampus. $A$, Typical BrdU-positive cells in the dentate gyrus of an adult rat hippocampus, as revealed with DAB visualized with Nomarski optics. Immunopositive nuclei are easily distinguishable and clearly separated, making them well suited for stereology counts. $B$, A higher magnification of the area marked in $A$ to show BrdU ${ }^{+}$nuclei in greater detail. Orientation in $A$ is dorsal $(D)$, ventral $(V)$, medial $(M)$, and lateral $(L)$. C, A BrdU ${ }^{+}$cell (red nucleus) within the granule cell layer also shows IGF-I receptor labeling (green signal surrounding the nucleus). $D$, Representative BrdU ${ }^{+}$nuclei in the hippocampus of an animal after $15 \mathrm{~d}$ of treadmill exercise and simultaneous infusion of nonblocking rabbit serum. $E, \mathrm{BrdU}^{+}$nuclei in the hippocampus of an exercised animal receiving a simultaneous inf usion of anti-IGF-I blocking antibody. Note that the number of BrdU nuclei is considerably lower after anti-IGF-I treatment. In both $D$ and $E$, image contrast is sharp to delineate easily the granule cell layer. $F$, Identification of BrdU-positive nuclei (green) as neurons using double fluorescence immunohistochemistry for $\beta$-tubulin III (red cytoplasm). Cells shown are located in the inner part of the granule layer. $G$, Whereas several GFAP-positive astrocytes (green) appeared in the dentate hilus with BrdU-positive nuclei (red), no GFAP-positive astrocytes appeared inside the granule layer. $G$, Granule cell layer; $H$, dentate hilus. Arrows indicate positive cells. $H-L$, Serial confocal microscopy images along the $z$-axis of the same neuron showing colocalization of BrdU ( yellow-green patches) in the nucleus and $\beta$-tubulin (red) in the cytoplasm to demonstrate the specificity of both signals.

any particular cell type because the ratio of neuron to glia and other types of cells did not differ between groups (Table 1).

\section{Circulating IGF-I is necessary for exercise-induced increases in the number of new hippocampal neurons}

Treadmill running significantly increases the number of $\mathrm{BrdU}^{+}$ nuclei in the hippocampus of adult rats (Figs. $2 I, J, 3 B, C$ ), confirming recent results in mice (van Praag et al., 1999). When exercising rats simultaneously received a chronic infusion of blocking anti-IGF-I antiserum, the enhancing effect of exercise on short-term survival (24 hr after last BrdU injection) as well as in long-term survival of $\mathrm{BrdU}^{+}$cells $(3$ weeks after last $\mathrm{BrdU}$ injection) was obliterated (Fig. 3B,C). Because the number of positive $\mathrm{BrdU}^{+}$nuclei in antiserum-injected animals was lower than in control sedentary animals (Fig. 3B,C), we determined whether administration of the anti-IGF-I antiserum to nonexercising rats would result in further reduction in the number of $\mathrm{BrdU}^{+}$nuclei in the hippocampus and found a significant de- crease in long-term survival of $\mathrm{BrdU}^{+}$cells after IGF-I antiserum treatment (Fig. 3C). As shown in Table 2, the proportion of neurons to glia and other cell types was not modified after any of the treatments.

\section{DISCUSSION}

The present results suggest that circulating IGF-I is necessary for the observed increase in the number of $\mathrm{BrdU}^{+}$hippocampal neurons produced by exercise. Two observations support this interpretation. First, subcutaneous administration of IGF-I as well as exercise to otherwise sedentary rats increase the number of $\mathrm{BrdU}^{+}$hippocampal granule cells. This agrees with previous findings indicating a stimulatory effect of IGF-I and of exercise on the number of new hippocampal neurons in adult hypophysectomized rats and in intact mice, respectively (van Praag et al., 1999; Aberg et al., 2000). Second, the stimulatory effect of exercise on number of $\mathrm{BrdU}^{+}$cells was completely inhibited by simultaneous 
Figure 3. Peripheral IGF-I increases the number of hippocampal $\mathrm{BrdU}^{+}$cells and is necessary for exercise-stimulated increases in hippocampal $\mathrm{BrdU}^{+}$cells in adult rats. $A$, Treatment for $7 \mathrm{~d}$ with a subcutaneous infusion of IGF-I $\left(50 \mathrm{mg} \cdot \mathrm{kg}^{-1} \cdot \mathrm{d}^{-1}\right)$ results in significantly increased number of $\mathrm{BrdU}^{+}$hippocampal granule cells. BrdU ${ }^{+}$ cells in the granule cell layer of the hippocampus are significantly increased in animals killed either $24 \mathrm{hr}(p<0.05)$ or 3 weeks $(p<0.005)$ after the last BrdU injection to determine short-term and longterm effects of IGF-I on $\mathrm{BrdU}^{+}$cell numbers, respectively. ${ }^{*} p<0.05 ;{ }^{* * *} p<0.005$ versus controls. $B, C$, Animals undergoing exercise training for $15 \mathrm{~d}$ and simultaneously receiving an infusion of nonblocking rabbit serum (NRS + exercise) show significant increases in $\mathrm{BrdU}^{+}$cells both 24 $\mathrm{hr}(B)$ as well as 2 weeks $(C)$ after the last BrdU injection as compared with nonexercising rats (controls) receiving an infusion of saline. However, both $24 \mathrm{hr}$ survival as well as 2 week survival of $\mathrm{BrdU}^{+}$cells are significantly reduced when exercising animals receive an infusion of blocking anti-

IGF-I antiserum (anti-IGF-I + exercise). Furthermore, infusion of anti-IGF-I to normal sedentary rats (control + anti-IGF-I) results in a significant decrease in long-term survival of $\mathrm{BrdU}^{+}$cells. ${ }^{*} p<0.01$ versus control; ${ }^{* *} p<0.01$ versus NRS + exercise; ${ }^{* * *} p<0.01$ versus control. Data are the mean $\pm \mathrm{SEM}$ of the number of $\mathrm{BrdU}^{+}$cells per cubic millimeter.

Table 1. Phenotypes of BrdU-positive cells in the hippocampus after IGF-I treatment

\begin{tabular}{lcr} 
& C & \multicolumn{1}{c}{ IGF-I } \\
\hline Proliferation $(24 \mathrm{hr})$ & $70 \pm 2$ & $66.6 \pm 5.1$ \\
$\quad$ Neuron & $2.5 \pm 0.6$ & $3 \pm 1.1$ \\
Astrocyte & $27.5 \pm 0.5$ & $30.4 \pm 1$ \\
$\quad$ Other & & \\
Survival (3 weeks) & $75.6 \pm 4$ & $76.3 \pm 1.5$ \\
$\quad$ Neuron & $4.2 \pm 0.6$ & $6 \pm 1.5$ \\
Astrocyte & $20.2 \pm 2$ & $17.7 \pm 1.4$ \\
Other &
\end{tabular}

Numbers are mean \pm SEM of percentage of cells labeled with each specific marker. C, Controls receiving saline infusion for $7 \mathrm{~d}$. IGF-1, Animals receiving IGF-1 infusion for $7 \mathrm{~d}$.

infusion of a blocking anti-IGF-I rabbit antiserum but not by infusion of a normal rabbit serum. However, this interpretation needs to be qualified in two ways. The number of $\mathrm{BrdU}^{+}$hippocampal granule cells was comparable after 1 week of $\mathrm{BrdU}+$ IGF-I infusion or 2 weeks of BrdU + exercise. Because we did not check the IGF-I concentration in CSF under both conditions or the effect of the same concentration of IGF-I for 1 or 2 weeks, we cannot really say that one treatment (IGF-I infusion) mimics the effect of the other one (exercise), although this could well be the case. The other caveat is that we do not know it the anti-IGF-I antiserum entered the brain and affected directly the production, survival, or BrdU labeling of new hippocampal neurons. None of the latter effects have been described, but in principle they are possible. Despite these lacunae in our knowledge, we suggest that exercise affected the number of $\mathrm{BrdU}^{+}$hippocampal granule cells by increasing the presence of IGF-I in brain tissue. We also suggest that anti-IGF-I treatment cancelled the effect of exercise by blocking the entrance of IGF-I into the brain.

These findings extend and reinforce our previous observations on the role of circulating IGF-I as a mediator of the effects of
Table 2. Phenotypes of BrdU-positive cells in the hippocampus after exercise training during $15 \mathrm{~d}$

\begin{tabular}{lcrrr} 
& & & E + & C + \\
& C & E + NRS & IGF-I Ab & \multicolumn{1}{c}{ IGF-I Ab } \\
\hline Proliferation (24 hr) & & & & \\
$\quad$ Neuron & $75 \pm 1$ & $78.6 \pm 1.1$ & $76.6 \pm 3$ & $74.2 \pm 0.4$ \\
$\quad$ Astrocyte & $1.9 \pm 0.5$ & $4.7 \pm 2.2$ & $2 \pm 1$ & $2.5 \pm 1.3$ \\
$\quad$ Other & $22.9 \pm 0.4$ & $16.7 \pm 0.9$ & $21.4 \pm 1.5$ & $23.1 \pm 0.3$ \\
Survival (2 weeks) & & & & \\
$\quad$ Neuron & $77.6 \pm 0.5$ & $82.3 \pm 2.5$ & $80 \pm 2$ & $78.9 \pm 1.2$ \\
$\quad$ Astrocyte & $2.9 \pm 1$ & $2.5 \pm 2.5$ & $5.1 \pm 2$ & $3.7 \pm 0.4$ \\
$\quad$ Other & $19.5 \pm 0.1$ & $15.2 \pm 0.5$ & $14.9 \pm 0.5$ & $17.4 \pm 1.2$
\end{tabular}

Numbers are mean \pm SEM of percentage of cells labeled with each specific marker. C, Controls receiving saline infusion for $15 \mathrm{~d}$. E + NRS, Exercising animals receiving simultaneous infusion of normal rabbit serum. E + IGF-I Ab, Exercising animals receiving infusion of a blocking anti-IGF1 antiserum. C + IGF-I Ab, Control animals receiving infusion of a blocking anti-IGF1 antiserum.

exercise on the brain (Carro et al., 2000). Thus, we found that after acute exercise, accumulation of blood-borne IGF-I into specific areas of the brain, including the hippocampus, can be inhibited by intraventricular infusion of a blocking antibody plus an IGF-I receptor antagonist. This procedure also inhibited the exercise-induced increase in c-fos labeling of the hippocampus and other brain areas (Carro et al., 2000). Because acute systemic administration of IGF-I mimics other effects of acute exercise on the brain such as increased expression of BDNF in the hippocampus and increased c-fos labeling throughout the brain (Carro et al., 2000), we suggest that circulating IGF-I is critically involved in the effects of exercise on brain function.

Both internal as well as external factors modulate the number of new neurons in the adult mammalian brain (McKay, 1997). Among the latter, enriched environment, psychosocial stress, learning, and exercise all have been shown to stimulate proliferation and/or survival of new dentate granule cells (Gould et al., 
1999). In vitro and in vivo studies have shown that intrinsic modulators of the proliferation and survival of new hippocampal neurons include a variety of growth factors and hormones, such as corticosteroids, IGF-I, or fibroblast growth factor (FGF)-2 (Cameron and Gould, 1994). Our present findings indicate that an extrinsic stimulator of the number of new hippocampal granule cells such as physical exercise upregulates brain IGF-I levels, which in turn also increases the number of $\mathrm{BrdU}^{+}$cells in the hippocampus. Other stimuli of hippocampal cell proliferation and/or survival such as seizures or ischemia also increase endogenous growth factors and hormones (Hughes et al., 1999). It is thus possible that the mechanism whereby extrinsic regulators of the number of new hippocampal neurons in the adult operate is by modulation of endogenous neurotrophic factors and hormones. In support of the latter, recent work in birds indicates that an extrinsic modulator of new neuron survival such as singing behavior upregulates expression of BDNF in relation to the amount of singing, and this correlates with the extent of new neuron survival ( $\mathrm{Li}$ et al., 2000). We can also speculate that factors such as aging or stress that reduce the number of new neurons through upregulation of endogenous corticosteroids (McEwen, 1996; Gould and Tanapat, 1999) may eventually modulate availability of endogenous neurotrophic factors such as IGF-I. Indeed, corticosteroids exert inhibitory effects on the synthesis of IGF-I by the liver, the main source of blood-borne IGF-I (Yakar et al., 1999). Furthermore, blood and brain levels of IGF-I decrease with age (Cohen et al., 1992). In addition, previous observations indicated that blood-borne IGF-I upregulates the number of $\mathrm{BrdU}^{+}$cells in the adult hippocampus under basal conditions because hypophysectomized rats with very low levels of serum IGF-I have a lower number of new neurons that recovers to levels seen in intact animals after injection of IGF-I (Aberg et al., 2000). Our present results support these findings because sedentary animals receiving an infusion of blocking anti-IGF-I antiserum show long-term survival of $\mathrm{BrdU}^{+}$cells significantly lower than control rats. Thus, it is possible that the basal number of new hippocampal neurons in the adult is modulated by circulating neurotrophic factors such as IGF-I.

Other neurotrophic factors such as FGF-2 and BDNF have also been proposed to participate in exercise-induced increases in the number of new hippocampal neurons (van Praag et al., 1999). This is based on the observation that exercise stimulates their expression in the hippocampus (Neeper et al., 1995; GomezPinilla et al., 1997). However, whereas recent findings indicate that IGF-I increases the number of new hippocampal neurons (Aberg et al., 2000), this is not the case for either BDNF or FGF-2. Although IGF-I induces expression of BDNF in the hippocampus (Carro et al., 2000), potentially supporting a role for BDNF in IGF-I stimulated increased survival of new neurons, BDNF does not appear to be involved in hippocampal cell survival at least during embryonic life because BDNF null mutants do not show major deficits in this brain area (Jones et al., 1994). On the contrary, IGF-I knock-outs show specific decreases in hippocampal granule neurons (Beck et al., 1995), suggesting an important role for IGF-I in fetal proliferation and/or survival of new neurons. This might be significant because regulation of these events by growth factors in the adult is thought to be similar to the embryonic period (Brooker et al., 2000). Furthermore, whereas FGF-2 increases the number of $\mathrm{BrdU}^{+}$cells in the adult olfactory bulb and in the subventricular zone, it does not affect the number of new cells in the hippocampus (Wagner et al., 1999).
$\mathrm{BrdU}^{+}$cells in the granular zone of dentate gyrus of the hippocampus express IGF-I receptors, which suggests that IGF-I can directly affect them. In addition, neocortical precursor cells in culture express IGF-I receptors and proliferate in the presence of IGFs (Nielsen et al., 1991). These precursor cells also secrete IGF-I, which acts in an autocrine-paracrine way to promote their survival (Drago et al., 1991). Thus, IGF-I may increase the number of $\mathrm{BrdU}^{+}$cells in the adult hippocampus by increasing proliferation of precursor cells, their survival, or both. However, this has yet to be directly addressed in future studies.

We and others have found that peripheral administration of IGF-I exerts potent therapeutic effects in several models of brain damage (Fernandez et al., 1998; Pulford et al., 1999). The possibility that IGF-I could also prove of therapeutic value in hippocampal-related diseases, in particularly those affecting memory processes, has already been discussed (Aberg et al., 2000). Our results add further support to this idea because exercise improves cognition (Kramer et al., 1999), and IGF-I ameliorates memory deficits in aging rats (Markowska et al., 1998). These data also provide a possible explanation for the beneficial effects of physical exercise on the response to neurodegeneration in diseases such as Alzheimer's, where IGF-I levels are also altered (Tham et al., 1993). Furthermore, because recent evidence indicates that new neurons appear in the adult brain in response to injury in areas where under normal circumstances they are not formed (Magavi et al., 2000), it is conceivable that the wide neuroprotective effects of IGF-I include modulation of the number of new neurons in damaged areas.

In summary, the present findings provide a possible mechanism whereby physical exercise modulate the number of new hippocampal neurons in the adult. We may start considering the brain as a major target organ for blood-borne IGF-I.

\section{REFERENCES}

Aberg MA, Aberg ND, Hedbacker H, Oscarsson J, Eriksson PS (2000) Peripheral infusion of IGF-I selectively induces neurogenesis in the adult rat hippocampus. J Neurosci 20:2896-2903.

Azcoitia I, Sierra A, Garcia-Segura LM (1999) Neuroprotective effects of estradiol in the adult rat hippocampus: interaction with insulin-like growth factor-I signalling. J Neurosci Res 58:815-822.

Beck KD, Powell-Braxton L, Widmer HR, Valverde J, Hefti F (1995) Igf1 gene disruption results in reduced brain size, CNS hypomyelination, and loss of hippocampal granule and striatal parvalbumincontaining neurons. Neuron 14:717-730.

Boyes BE, Kim SU, Lee V, Sung SC (1986) Immunohistochemical colocalization of S-100b and the glial fibrillary acidic protein in rat brain. Neuroscience 17:857-865.

Brooker GJ, Kalloniatis M, Russo VC, Murphy M, Werther GA, Bartlett PF (2000) Endogenous IGF-1 regulates the neuronal differentiation of adult stem cells. J Neurosci Res 59:332-341.

Busiguina S, Fernandez AM, Barrios V, Clark R, Tolbert DL, Berciano J, Torres-Aleman I (2000) Neurodegeneration is associated to changes in serum insulin-like growth factors. Neurobiol Dis 7:657-665.

Cameron HA, Gould E (1994) Adult neurogenesis is regulated by adrenal steroids in the dentate gyrus. Neuroscience 61:203-209.

Cameron HA, Woolley CS, McEwen BS, Gould E (1993) Differentiation of newly born neurons and glia in the dentate gyrus of the adult rat. Neuroscience 56:337-344.

Carro E, Nunez A, Busiguina S, Torres-Aleman I (2000) Circulating insulin-like growth factor I mediates effects of exercise on the brain. J Neurosci 20:2926-2933.

Cohen P, Ocrant I, Fielder PJ, Neely EK, Gargosky SE, Deal CI, Ceda GP, Youngman O, Pham H, Lamson G (1992) Insulin-like growth factors (IGFs): implications for aging. Psychoneuroendocrinology 17:335-342.

Crespo D, Stanfield BB, Cowan WM (1986) Evidence that lategenerated granule cells do not simply replace earlier formed neurons in the rat dentate gyrus. Exp Brain Res 62:541-548.

Drago J, Murphy M, Carroll SM, Harvey RP, Bartlett PF (1991) Fibroblast growth factor-mediated proliferation of central nervous system precursors depends on endogenous production of insulin-like growth factor I. Proc Natl Acad Sci USA 88:2199-2203. 
Easter Jr SS, Ross LS, Frankfurter A (1993) Initial tract formation in the mouse brain. J Neurosci 13:285-299.

Eliakim A, Moromisato M, Moromisato D, Brasel JA, Roberts C Jr, Cooper DM (1997) Increase in muscle IGF-I protein but not IGF-I mRNA after 5 days of endurance training in young rats. Am J Physiol 273:R1557-R1561.

Feldman EL, Sullivan KA, Kim B, Russell JW (1997) Insulin-like growth factors regulate neuronal differentiation and survival. Neurobiol Dis 4:201-214.

Fernandez AM, de la Vega AG, Torres-Aleman I (1998) Insulin-like growth factor I restores motor coordination in a rat model of cerebellar ataxia. Proc Natl Acad Sci USA 95:1253-1258.

Gage FH, Kempermann G, Palmer TD, Peterson DA, Ray J (1998) Multipotent progenitor cells in the adult dentate gyrus. J Neurobiol 36:249-266.

Garcia-Segura LM, Rodriguez JR, Torres-Aleman I (1997) Localization of the insulin-like growth factor I receptor in the cerebellum and hypothalamus of adult rats: an electron microscopic study. J Neurocytol 26:479-490.

Gomez-Pinilla F, Dao L, So V (1997) Physical exercise induces FGF-2 and its mRNA in the hippocampus. Brain Res 764:1-8.

Gould E, Tanapat P (1999) Stress and hippocampal neurogenesis. Biol Psychiatry 46:1472-1479.

Gould E, Beylin A, Tanapat P, Reeves A, Shors TJ (1999) Learning enhances adult neurogenesis in the hippocampal formation. Nat Neurosci 2:260-265.

Hatton WJ, von Bartheld CS (1999) Analysis of cell death in the trochlear nucleus of the chick embryo: calibration of the optical disector counting method reveals systematic bias. J Comp Neurol 409:169-186.

Howard CV, Reed MG (1998) Unbiased stereology. Three-dimensional measurements in microscopy. Oxford: BIOS Scientific.

Hughes PE, Alexi T, Walton M, Williams CE, Dragunow M, Clark RG, Gluckman PD (1999) Activity and injury-dependent expression of inducible transcription factors, growth factors and apoptosis-related genes within the central nervous system. Prog Neurobiol 57:421-450.

Jones KR, Farinas I, Backus C, Reichardt LF (1994) Targeted disruption of the BDNF gene perturbs brain and sensory neuron development but not motor neuron development. Cell 76:989-999.

Kosaka T, Hama K (1986) Three-dimensional structure of astrocytes in the rat dentate gyrus. J Comp Neurol 249:242-260.

Kramer AF, Hahn S, Cohen NJ, Banich MT, McAuley E, Harrison CR, Chason J, Vakil E, Bardell L, Boileau RA, Colcombe A (1999) Ageing, fitness and neurocognitive function. Nature 400:418-419.

Li XC, Jarvis ED, Alvarez-Borda B, Lim DA, Nottebohm F (2000) A relationship between behavior, neurotrophin expression, and new neuron survival. Proc Natl Acad Sci USA 97:8584-8589.

Magavi SS, Leavitt BR, Macklis JD (2000) Induction of neurogenesis in the neocortex of adult mice. Nature 405:951-955.
Markowska AL, Mooney M, Sonntag WE (1998) Insulin-like growth factor-1 ameliorates age-related behavioral deficits. Neuroscience 87:559-569.

McEwen BS (1996) Gonadal and adrenal steroids regulate neurochemical and structural plasticity of the hippocampus via cellular mechanisms involving NMDA receptors. Cell Mol Neurobiol 16:103-116.

McKay R (1997) Stem cells in the central nervous system. Science 276:66-71.

Neeper SA, Gomez-Pinilla F, Choi J, Cotman C (1995) Exercise and brain neurotrophins. Nature 373:109.

Nielsen FC, Wang E, Gammeltoft S (1991) Receptor binding, endocytosis, and mitogenesis of insulin-like growth factors I and II in fetal rat brain neurons. J Neurochem 56:12-21.

Paxinos G, Watson C (1982) The rat brain in stereotaxic coordinates. New York: Academic.

Pixley SK, de Vellis J (1984) Transition between immature radial glia and mature astrocytes studied with a monoclonal antibody to vimentin. Brain Res 317:201-209.

Pulford BE, Whalen LR, Ishii DN (1999) Peripherally administered insulin-like growth factor-I preserves hindlimb reflex and spinal cord noradrenergic circuitry following a central nervous system lesion in rats. Exp Neurol 159:114-123.

Sjogren K, Liu JL, Blad K, Skrtic S, Vidal O, Wallenius V, LeRoith D, Tornell J, Isaksson OG, Jansson JO, Ohlsson C (1999) Liver-derived insulin-like growth factor I (IGF-I) is the principal source of IGF-I in blood but is not required for postnatal body growth in mice. Proc Natl Acad Sci USA 96:7088-7092.

Stanfield BB, Trice JE (1988) Evidence that granule cells generated in the dentate gyrus of adult rats extend axonal projections. Exp Brain Res 72:399-406.

Tham A, Nordberg A, Grissom FE, Carlsson-Skwirut C, Viitanen M, Sara VR (1993) Insulin-like growth factors and insulin-like growth factor binding proteins in cerebrospinal fluid and serum of patients with dementia of the Alzheimer type. J Neural Transm Park Dis Dement Sect 5:165-176.

Torres-Aleman I (1999) Insulin-like growth factors as mediators of functional plasticity in the adult brain. Horm Metab Res 31:114-119.

van Praag H, Kempermann G, Gage FH (1999) Running increases cell proliferation and neurogenesis in the adult mouse dentate gyrus. Nat Neurosci 2:266-270

Wagner JP, Black IB, DiCicco-Bloom E (1999) Stimulation of neonatal and adult brain neurogenesis by subcutaneous injection of basic fibroblast growth factor. J Neurosci 19:6006-6016.

Yakar S, Liu JL, Stannard B, Butler A, Accili D, Sauer B, LeRoith D (1999) Normal growth and development in the absence of hepatic insulin-like growth factor I. Proc Natl Acad Sci USA 96:7324-7329. 